\title{
Exploration of College English Language Teacher from the Perspective of Communication Science
}

\author{
Changzhen Ju \\ Wuhan Donghu University, Wuhan Hubei, 430212, China
}

Key words: Perspective of communication science, College English, Language teaching.

\begin{abstract}
As an important component element in college English teaching, English language teaching also plays an important role in cultivating students' English quality. Therefore, in this new era, college English teachers need to analyze college English language teaching from the perspective of communication science based on the current need of talent cultivation, so as to provide corresponding guidance for implementation of college English language teaching activities and help to significant promote the quality of college English teaching in our country.
\end{abstract}

\section{Introduction}

In recent years, the development of media transmission industry and the wide application of network technology in society have also influenced the educational and teaching activities in colleges; all majors began to explore more scientific teaching modes in combination with their own development directions in the hope of further raising their educational quality and providing students with professional teaching guidance. Therefore, for the implementation of college English teaching, it is also required to recognize the current social changes, combine the relatively scientific perspective of communication science to optimize and adjust its own teaching activities and explore a more professional teaching mode to provide students with scientific educational service and offer corresponding guarantee for cultivating students into talents who meet the social need. Based on the influence of media communication on college English teaching, this paper properly analyzed the major teaching objectives of college English language teaching on the current social background and explored the corresponding educational reform measures, in the hope of really raising the level of English education in colleges and helping students majoring in English in colleges of China to obtain better development.

\section{The current influence of media communication on college English teaching in China}

The development of news media industry is mainly supported by the application of computer technology and the news media spread all sorts of information to all sectors of society every day during its development process. If the advantage of media communication can be fully utilized in English teaching practice, teachers can enrich the teaching contents, effectively arouse students' learning enthusiasm and lay a solid foundation for the strengthening of learning effect. On the basis of this, before reform in college English language teaching activities, teachers need to fully understand the influence of media communication on English teaching, reasonably adjust teaching activities based on this influence and provide solid guarantee for the strengthening of teaching quality.

Firstly, under the influence of media communication, college English teaching shows an obvious tendency of interactive development. In the new era, the further development of media communication technology and its wide application in the educational field have increased the interaction in related educational activities in China and create conditions for the deepening of 
educational reform. Under the influence of interaction of media communication, teachers can timely obtain corresponding information feedbacks from teaching activities, thus adjust the teaching process by combining the feedback result and students' learning state, and provide students with more all-around basic learning conditions while enhancing the pertinence of teaching ${ }^{[1]}$. Meanwhile, the influence of media communication on English teaching is also shown in the significant improvement in the interaction, interestingness and link of English teaching in China as well as the solid foundation laid for the implementation of English teaching. As shown in related investigations and researches, as for media news communication, the public highly identifies the news information with strong interaction. This is also the same in the field of English education. Only when teachers take some measures to raise the teaching interaction, can they effectively stimulate students' enthusiasm to participate in teaching activities; then, students can rapidly master the corresponding learning methods in the English learning process and thus obtain greater learning effects.

Secondly, under the influence of media communication, college English teaching can realize the high-quality control over redundant information. The development of media communication technology has exerted a great influence on China' s college English teaching and the influence is specifically shown in the good control over the redundancy of teaching information in English language teaching activities. In English teaching practice, English teachers can reasonably integrate related information on media with the assistance of all sorts of auxiliary media forms so as to maximally avoid the adverse effects of the occurrence of repeated information on the strengthening of students' learning efficiency. Meanwhile, as for some educational information requiring repeated emergence, teachers can also use media communication to optimize and adjust the way of information repetition so as to help students to naturally accept repeated teaching information and provide solid guarantee for the enhancement of teaching effect ${ }^{[2]}$. Meanwhile, the phenomenon of polysemy is usually relatively restricted and not desired in China' s college English teaching; this problem can be solved with media communication, which can reasonably controls the related multivocal information delivered by other media and further offset the polysemy in English teaching in virtue of the interaction among media so as to increase the flexibility of English teaching and promote the further strengthening of English teaching effect.

\section{Basic objective and requirements of college English language teaching of China in the new era}

Under the influence of current economic globalization of China, our country has gradually attached more importance to the development of international economy and trade since its access to the WTO and has established long-term trade relations with many countries in the world, largely facilitating the further development of economic society of China. Based on this, the society has relatively high requirements for the cultivation of English talents in colleges, which promoted the significant improvement in the quality of college English teaching of China to some extent. Under this influence, the teaching for college English major was also properly adjusted and scientific innovations were made on English language teaching based on the demand for talents in the market so as to guarantee the English talents cultivated by the colleges to really meet the social need and offer corresponding supports for the construction and development of China' s economic society ${ }^{[3]}$. In the specific teaching practice in colleges, some colleges have reasonably revised related standards involved in English teaching activities at the present stage and clearly pointed out that the major goal of college English teaching activities in China was to cultivate students' English language ability, in the hope of gradually improving students' reading, listening, speaking and writing ability etc. on the basis of enhancing their English language ability and providing corresponding guarantee for students' sound development in the future.

Make a comprehensive analysis on the English teaching syllabus currently adopted by Chinese colleges. At this stage, in college English education practice, teachers not only should ask students to master some English language knowledge but also hope to cultivate students' cross-culture communication ability with English language knowledge so as to practically improve students' English quality and lay a solid foundation for the better development of students in the future. 
Therefore, college teachers must explore more scientific modes of talent cultivation in combination with the market need, optimize and adjust the English language teaching work, help to strengthen students' practical ability to use English language on the basis of giving full play to the influence of environment for college English language and guarantee that students can apply the English knowledge learned by them in English teaching practice after graduation and thus can achieve better vocational development ${ }^{[4]}$. Based on this, college English teachers should pay more attention to the optimization of English language environment, help students to really use English language they' ve learned in broadcast, newspaper, speech contests and other activities on the campus and in social life, help to train students' English expression and interpersonal skills, make students to be unconsciously influenced by the English language environment when they actively participate in related teaching activities, gradually improve students' comprehensive English quality and lay a foundation for students' future development. As a modern technology, media communication can support the current construction of English language environment in colleges, help students to participate in more abundant teaching activities with the assistance of computer and internet, raise the pertinence and effectiveness of English teaching, simultaneously promote to give full play to the influence of English language environment, and lay a solid foundation for the strengthening of quality of college English language teaching and talent cultivation.

\section{Basis measures for further strengthening college English language teaching under the visual threshold of communication science}

In the English teaching practice in colleges, teachers are the organizers and leaders of teaching activities, so college English teachers should fully clarify the characteristics of current college student audience group in the teaching information reception when organizing students to participate in English language communication activities, then properly permeate communication skills in the process of practical teaching explanation, give targeted educational guidance for students by taking full advantage of the feedback analysis on communication effect and enhance the quality of language teaching on the basis of realizing efficient communication of English language teaching information.

\section{Communication-based college English language teaching should break through the restriction of traditional teaching relationship pattern}

In the research field of mass communication in China, the relationship between teachers and students is absolutely not limited to the simple teaching and unilateral imparting of knowledge. There is a favorable information interaction relationship between the knowledge disseminator and receiver; besides, teachers can complete the transmission of knowledge with information media and related communication activities, maximally enhance the teaching effect and help to give full play to teaching work. Specifically speaking, in the process of implementing the transmission of knowledge, there must be some behavioral and psychological interactions between the knowledge disseminator and receiver. Therefore, from the vision threshold of communication, to reach a favorable effect, college English teaching should break through the restriction of the traditional unilateral teaching relationship, really change the unilateral communication of English language knowledge into the more scientific two-way communication, highlight students' dominant position in teaching activities, achieve equal dialogues and communications between teachers and students in teaching activities, enhance the teaching effect through favorable teaching interaction, and provide corresponding guarantee for the enhancement of quality of college education.

\section{Further pay more attention to the application of communication skills}

With the further development of the exploration in college English teaching practice in the new era, English teachers should permeate some thoughts of era spirit in their teaching practices, explore the teaching methods which can adapt to the modern educational concept, and effectively enhance the pertinence and purposiveness of English language teaching by flexibly matching and combining such teaching methods so as to enhance the quality of English language teaching and guarantee that the 
talent cultivation in colleges can adapt to the new social development tendency in the new era. In the field of communication science, in essence, college English teachers' exploration in English teaching methods is the exploration in knowledge communication skills; to be specific, it means a special and specific communication mode to flexibly use the related communication principle to realize the expected communication goal in persuasive communication activities. Therefore, college English teachers can properly use the concept of communication in their exploration in teaching methods, seek more scientific communication skills while spreading related English language knowledge to students and give targeted educational guidance to students according to their practical conditions so as to enhance the scientificity in English teaching, guarantee that English language teaching activities can be accepted by more students and lay a solid foundation for the enhancement of English education quality ${ }^{[5]}$.

\section{Reasonably use the new media technology to improve the quality of college English language teaching}

In the new era, the further development of China' s internet information technology has led to the gradually increasing contacts between the public and network and the significant increase in the number of Chinese netizens, which, to some extent, exerted specific influences on college English language teaching. On this social background, the development of network has provided rich teaching resources for college English teaching. Besides, the emergence of new network media also caused some changes in China' s media forms; the new media form has exerted specific influences on college students' learning life. Therefore, as for the optimization and adjustment of college English language teaching activities based on the thought of communication, it is also required to intensify the influence of new media resources on English language teaching in communication activities. In educational practices, college English teachers reasonably use the tool of new media to effectively enhance the interestingness of classroom teaching with the help of the new media resources in the communication field, fully arouse students' learning enthusiasm, and implement the dissemination of English language knowledge by means of images, acoustic images and many other ways so as to fully stimulate students' multiple sense organs to further strengthen students' learning effect and lay a foundation for the improvement in the quality of college English language teaching. Meanwhile, with the advantage of network, college English teachers can also create a corresponding learning platform for students, where students can freely air their opinions concerned and can equally communicate and exchange with other students and teachers. On the basis of gradually enhancing the effect of dissemination of English language knowledge, teachers can also promote students to accept good educational guidance, obtain the best English teaching effects and provide corresponding guarantee for the cultivation of students' English language ability.

\section{Conclusion}

To sum up, based on the market need in the new era, college English teachers must optimize and adjust the teaching methods and mode by combining the practical condition, further enhance the enthusiasm for educational practice activities. Only in this way, can they improve the quality of English language teaching and lay a foundation for the cultivation of students' comprehensive English ability. Therefore, college English teachers can explore more scientific English language teaching modes with the assistance of the thoughts of communication science, enhance the interaction and pertinence of English language teaching, build favorable English language learning environments for students, help to consciously and gradually enhance students' comprehensive quality and create conditions for training students as talents needed by the society.

\section{References}

[1] Zuo Lingling. Study on discourse strategies of teachers for college English for non-English majors from the perspective of communication, Youth Literator, 2013(35):248-248. 
[2] Wang Lin. Study on English translation of contemporary words with Chinese cultural characteristics from the perspective of cross-culture communication, Qufu Normal University, 2013.

[3] Yang Yahui. Study on the editing and translation of news on English homepages of "985" colleges from the perspective of communication, China University of Geosciences (Wuhan), 2013.

[4] Yang Ying. Test of college English language level from the perspective of multi-mode discourse theory, Journal of Taiyuan City Vocational College, 2013(11):124-125.

[5] Peng Lule. An humble opinion on the construction of English language laboratory, Journal of Chifeng University (natural science), 2013(8):194-195. 